\title{
BIO.03 - Development, characterization and validation of interfering RNA carrier liposomes for breast cancer treatment
}

Alice Sampaio Barreto da Rocha ${ }^{1 *}$; Beatriz Ferreira de Carvalho Patricio ${ }^{2}$; Helvécio Vinícius Antunes Rocha ${ }^{2}$; Bruno Vinícius da Conceição Souza ${ }^{1}$; Patrícia Cristina da Costa Neves; Natália Yoshihara ${ }^{3}$; Braúlio Archanjo ${ }^{3}$; Tatiana Martins Tilli; Ana Paula Dinis Ano Bom ${ }^{1}$.

1Fiocruz/Bio-Manguinhos;

2Fiocruz/Farmanguinhos;

3INMETRO;

4Fiocruz/CDTS.

Introduction: Breast cancer has the highest incidence and mortality rates among women worldwide. Taking into account the adverse effects of current treatments, it is necessary to minimize damages to patients and increase treatment specificity.

Objective: This project focuses on nanomedicine as an approach for cancer's therapy through the development of RNAi liposome carrier for target genes for breast cancer.

Methodology: Lipid film hydration methodology was used for liposomes' development. For this step, cationic formulation was developed. For physical-chemical characterization, liposomes were submitted to dynamic light scattering (DLS), Zeta Potential and Transmission Electron Microscopy techniques. We also performed stability tests: 1) Long term stability Prolonged aging under storage at $4^{\circ} \mathrm{C}$ for 1 month, 2) Resistance to centrifugation and 3) Freeze-thawing at $-18^{\circ} \mathrm{C}$. For empty liposome cytotoxic's test, tumoral lineages MCF-7 (human breast adenocarcinoma; luminal-A), MDA-MB-231 (human breast adenocarcinoma; triple negative) and MFC-10A (human breast epithelial cell; non-tumoral) were used in MTT assay and were evaluated at 24, 48 and $72 \mathrm{~h}$ intervals after treatment. After selection of the formulation, we encapsulate the RNAi. The encapsulation efficiency was analyzed by separating the unencapsulated RNAi by ultrafiltration and subsequent dosing of both samples by absorbance at $260 \mathrm{~nm}$ using Nanodrop 1000.

Results: DLS charactetization shows particles sizing 100 to $120 \mathrm{~nm}$, a polydispersity index of 0.1 to 0.2 and positive potential of $50 \mathrm{mV}$ to $70 \mathrm{mV}$ for cationic liposomes. Micrograph's confirmed expected sizes of approximately $100 \mathrm{~nm}$. These results corroborate the parameters established in the literature. Liposomal stability test on aging of the sample under storage at $4^{\circ} \mathrm{C}$ showed no changes in size, PDI and zeta potential, as the liposome proved to be resistant to centrifugations and freezing thawing at $-18^{\circ} \mathrm{C}$. Results indicates that empty liposome has no effect into cell's viability. The encapsulation efficiency analysis indicates a mean encapsulation of $90 \%$.

Conclusion: Based on this approach it's expected: 1) Provide more stability and permanence of RNAi in circulation, 2) Delivery of RNAi to tumor cells acting on translation blocking of breast cancer target proteins. As a perspective, this study will also contribute to the establishment of new studies focused on nanotechnology at Fiocruz.

Keywords: Breast cancer; Liposomes; RNAi 